\title{
Caracterização da qualidade acústica de salas de aula para prática e ensino musical
}

\author{
Caracterization of the acoustic quality of classrooms for \\ musical practice and teaching
}

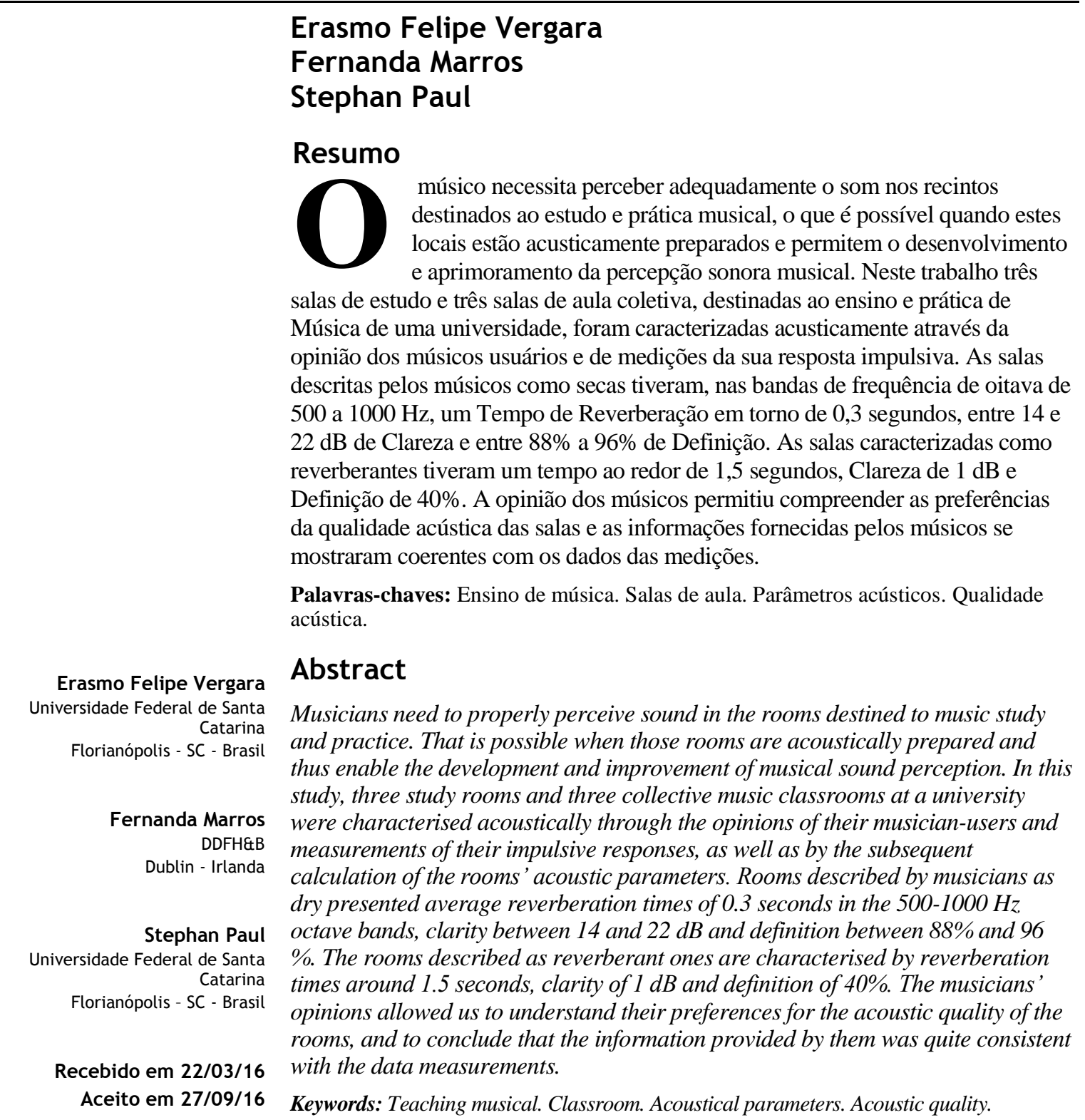




\section{Introdução}

Uma das questões que mais preocupam na área de ensino e aprendizagem musical é a condição acústica dos edifícios educacionais, em que a música deve ser ouvida com clareza e boa inteligibilidade, tanto quanto o discurso, porque em atividades de ensino a palavra falada sempre está presente. No caso do Brasil, a falta de atenção no que se refere à acústica nas edificações destinadas ao ensino de música prejudica a preparação dos músicos. Ademais, não existem normativas brasileiras que recomendem procedimentos de avaliação e parâmetros acústicos apropriados para salas de aula de ensino de música.

A formação dos músicos e futuros professores de música adquiriu novo significado e maior importância a partir da substituição da Lei de Diretrizes e Bases da Educação (LDB), Lei n. 9.394/1996, pela Lei n. 11.769/2008, referente à obrigatoriedade do ensino da música nos currículos escolares. Afortunadamente, esta lei trouxe diversas discussões e novas preocupações para todos os envolvidos no processo educativo, e as atenções se voltaram não somente para as metodologias de ensino a serem utilizadas, mas também para a estrutura física nas instituições de ensino.

Nesse contexto, da congregação do aprendizado com a música, estão inseridas as salas de aula para o ensino da música de um curso de graduação de uma universidade, salas estas utilizadas para atividades didáticas e artísticas. Com base na análise de duas tipologias de salas existentes - sala de estudo (SE) e sala de aula coletiva (SAC), esses recintos foram caracterizados acusticamente com uma avaliação qualitativa mediante entrevistas e questionários respondidos pelos músicos e também mediante medições acústicas com o uso da técnica da resposta impulsiva, conforme recomendações da norma ISO 3382-1 (INTERNATIONAL..., 2009). Uma sala de estudo é utilizada para a prática e o estudo individual ou em pequenos grupos de duas ou três pessoas, e é considerada pequena, com volume variando entre 60 e $80 \mathrm{~m}^{3}$. Uma sala de aula coletiva, com volume entre 160 e $330 \mathrm{~m}^{3}$, tem como característica a multifuncionalidade, sendo utilizada tanto para aulas coletivas quanto para a prática individual ou de pequenos grupos, além de receber audições e apresentações para público externo. Neste trabalho são analisados dois tipos de salas para ensino e prática musical (sala de estudo e sala de aula coletiva) visando relacionar os parâmetros acústicos objetivos determinados experimentalmente com os resultados da avaliação qualitativa feita pelos músicos sobre essas salas, de tal forma que se obtenham subsídios para projetos e melhoras acústicas desse tipo de ambiente.

\section{Parâmetros acústicos de salas de música}

A experiência musical tem que considerar a acústica do espaço onde a música é executada, pois, dependendo de como o recinto afeta o som que está sendo transmitido, o músico atua, consciente e inconscientemente, adaptando sua performance à acústica do ambiente (BERANEK, 1996; GADE, 2007; HATLEVIK, 2012; LOKKI, 2014). Por causa disso, na caracterização acústica de salas de ensino e prática musical é imprescindível considerar parâmetros relacionados à qualidade tanto da música quanto da palavra falada, já que esta é importante no processo de ensino, de forma que permita o adequado desenvolvimento profissional de um músico. Nesse sentido, os pré-requisitos acústicos essenciais para salas pequenas de música, com volume menor que $500 \mathrm{~m}^{3}$, devem ser elevada isolação sonora, tempos de reverberação curtos e uma distribuição homogênea das reflexões sonoras (TEUBER; VÖELKER, 1993; KOSKINEN; TOPPILA; OLKINUORA, 2010; OSMAN, 2010; HATLEVIK, 2012).

Atualmente, notam-se dois fatos importantes sobre o estudo acústico de ambientes musicais. Primeiro, os estudos estão voltados principalmente para salas de concerto, auditórios e teatros com volumes superiores a $500 \mathrm{~m}^{3}$; e segundo, os parâmetros existentes para a qualificação acústica, principalmente no que se refere à execução de música em ambientes fechados, carecem de esclarecimentos em relação aos tempos de reverberação e de decaimento inicial e à sensação de volume sonoro (BERANEK, 2003; VORLÄNDER; SUMMERS, 2008; BARRON, 2010; LONG, 2011).

Os valores de diversos parâmetros acústicos objetivos (tempo de reverberação, tempo de decaimento inicial, clareza, definição, etc.) de salas de apreciação e execução musical são obtidos com facilidade graças à tecnologia disponível hoje, porém não se conhece totalmente o que esses parâmetros representam e a forma como eles devem ser analisados. Além disso, muitos desses parâmetros acústicos são utilizados de forma exploratória, e são necessárias pesquisas a fim de validar sua importância e suas correlações com aspectos subjetivos (GADE, 2007; BRADLEY, 2011; LOKKI, 2014).

24 Vergara, E. F.; Marros, F.; Paul, S. 
Para salas de concerto musical destinadas à apresentação e audição com volumes superiores a $500 \mathrm{~m}^{3}$ o tempo de reverberação ideal pode variar entre $1,4 \mathrm{~s}$ e $2,0 \mathrm{~s}$ para a faixa de frequência de 500 a $1.000 \mathrm{~Hz}$ (BERANEK, 1996), enquanto os tempos de reverberação considerados adequados para salas pequenas, com volume menor que 400 $\mathrm{m}^{3}$, e dedicadas à prática e ensino musical podem variar entre 0,3 s e 1,2 s (LANE; MIKESKA, 1955; LAMBERTY, 1980; COHEN, 1992; TEUBER; VÖELKER, 1993; DEPARTMENT..., 2002; AMERICAN..., 2002; BUILDING..., 2003; LOKKI; SALMENSAARI, 2007; RYHERD, 2008), conforme mostrado no resumo da Tabela 1. Essas recomendações de valores médios de tempos de reverberação variam para cada tipo de instrumento (percussão, sopro, cordas) a ser executado na sala de aula, sendo para alguns instrumentos o valor do tempo de reverberação alto vantajoso, e em outros casos até prejudicial.

Outro parâmetro de qualidade acústica de um ambiente e relacionado com o decaimento da energia sonora é o tempo de decaimento inicial (early decay time - EDT), que considera somente os primeiros $10 \mathrm{~dB}$, o qual também é expresso em segundos. Tanto o tempo de reverberação quanto o tempo de decaimento inicial estão vinculados às propriedades físicas de salas. Gade (2007) e Kuttruff (2009) afirmam que o EDT tem-se correlacionado melhor com a reverberação percebida durante a execução da música e da fala. Além disso, o EDT é influenciado pelas reflexões iniciais, o que significa que depende mais da posição de medição. Dessa forma, o tempo de decaimento inicial é especialmente apropriado para analisar as diferenças de percepção sonora entre diversas posições dentro de recintos. Nesse sentido, porém, deve-se tomar cuidado com posições muito próximas à fonte, pois perto desta a energia sonora inicial decai abruptamente antes de iniciar um decaimento mais gradual (BRADLEY, 2011).

Tabela 1 - Tempos de reverberação médios para salas de prática e ensino musical

\begin{tabular}{|c|c|c|c|c|}
\hline Referência & $\begin{array}{l}\text { Prática/ensaio } \\
\text { conjunto }\end{array}$ & $\begin{array}{c}\text { Prática/ensaio } \\
\text { individual }\end{array}$ & $\begin{array}{c}\text { Ensino } \\
\text { (teoria musical) }\end{array}$ & $\begin{array}{c}\text { Frequência } \\
{[\mathrm{Hz}]}\end{array}$ \\
\hline Lane e Mikeska (1955) & - & 0,4 a $0,7 \mathrm{~s}$ & 0,55 a $0,8 \mathrm{~s}$ & 100 \\
\hline Karsai (1974) & - & $\begin{array}{l}0,8 \mathrm{~s}\left(105 \mathrm{~m}^{3}\right) \\
0,4 \mathrm{~s}\left(105 \mathrm{~m}^{3}\right)\end{array}$ & का & $\begin{array}{l}125 \\
500\end{array}$ \\
\hline Lamberty (1980) & - & $\begin{array}{c}0,5 \text { a } 0,9 \mathrm{~s} \\
\left(33-154 \mathrm{~m}^{3}\right)\end{array}$ & - & 500 \\
\hline Nagata (1989) & - & $0,3-0,5 \mathrm{~s}\left(100 \mathrm{~m}^{3}\right)$ & - & $125-4.000$ \\
\hline Cohen (1992) & $\begin{array}{l}0,3 \text { a } 0,5 \mathrm{~s} \\
\left(30-40 \mathrm{~m}^{3}\right)\end{array}$ & , & - & $125-4.000$ \\
\hline Teuber e Vöelker (1993) & $\begin{array}{c}0,2-0,6 \mathrm{~s} \\
\left(30-200 \mathrm{~m}^{3}\right)\end{array}$ & $\begin{array}{c}0,2-0,6 \mathrm{~s} \\
\left(30-200 \mathrm{~m}^{3}\right)\end{array}$ & $\begin{array}{c}0,2-0,6 \mathrm{~s} \\
\left(30-200 \mathrm{~m}^{3}\right)\end{array}$ & $63-10.000$ \\
\hline $\begin{array}{l}\text { American National } \\
\text { Standards Institute (2002) }\end{array}$ & $\begin{array}{c}<0,6 \mathrm{~s} \\
\left(38-150 \mathrm{~m}^{3}\right)\end{array}$ & $\begin{array}{c}<0,6 \mathrm{~s} \\
\left(14-30 \mathrm{~m}^{3}\right)\end{array}$ & $\begin{array}{c}<0,6 \mathrm{~s} \\
\left(120-210 \mathrm{~m}^{3}\right)\end{array}$ & $500-2.000$ \\
\hline Building Bulletin 93 (2002) & $\begin{array}{c}0,5-1,0 \mathrm{~s} \\
\left(38-150 \mathrm{~m}^{3}\right)\end{array}$ & $\begin{array}{c}0,3-0,6 \mathrm{~s} \\
\left(14-30 \mathrm{~m}^{3}\right)\end{array}$ & $\begin{array}{c}0,4-0,8 \mathrm{~s} \\
\left(120-210 \mathrm{~m}^{3}\right)\end{array}$ & $500-2.000$ \\
\hline Building Bulletin 93 (2003) & $\begin{array}{c}0,6 \text { a } 1,2 \mathrm{~s} \\
\left(38-150 \mathrm{~m}^{3}\right)\end{array}$ & $\begin{array}{c}<0,8 \mathrm{~s} \\
\left(14-30 \mathrm{~m}^{3}\right)\end{array}$ & $\begin{array}{c}<1,0 \mathrm{~s} \\
\left(120-210 \mathrm{~m}^{3}\right)\end{array}$ & $500-2.000$ \\
\hline Lokki e Salmensaari (2007) & $\begin{array}{c}0,7 \mathrm{~s} \\
\left(246 \mathrm{~m}^{3}\right)\end{array}$ & $\begin{array}{c}0,5-0,6 \mathrm{~s} \\
\left(10-120 \mathrm{~m}^{3}\right)\end{array}$ & $\begin{array}{c}0,5-0,6 \mathrm{~s} \\
\left(10-120 \mathrm{~m}^{3}\right)\end{array}$ & 1.000 \\
\hline Ryherd (2008) & 0,8 a $1,0 \mathrm{~s}$ & - & 0,4 a $0,5 \mathrm{~s}$ & \\
\hline
\end{tabular}


Quando um músico refere-se à definição (definition $-\mathrm{D}_{50}$ ) ou clareza (clarity $-\mathrm{C}_{80}$ ) está expressando o grau de distinção entre um som e outro em uma performance musical (BERANEK, 1996; GADE, 2007). Isso significa que uma sala apresenta um bom grau de clareza quando a música tocada nela soa bem definida, com articulações sonoras límpidas e precisas, independentemente do andamento. Caso contrário, o som se apresenta confuso e indefinido, principalmente em passagens mais rápidas (FIGUEIREDO, 2005). Em uma sala considerada seca, a clareza e a definição serão maiores do que numa sala reverberante, pois nesta o decaimento da energia sonora é mais lento e, portanto, mais energia estará concentrada na parte tardia da reverberação, diminuindo a razão entre energia inicial e final. Diferentes valores de clareza podem ser preferidos conforme as condições acústicas do local. Um maestro durante um ensaio, por exemplo, prefere salas com clareza entre +1 e +5 $\mathrm{dB}$, entretanto em uma situação de apresentação, com audiência, o mesmo maestro geralmente prefere uma sala mais reverberante, com clareza entre -1 e -4 dB (BERANEK, 1996). Cabrera (2007) mostra que salas de audição e salas de prática musical com volumes entre 10 e $300 \mathrm{~m}^{3}$ podem alcançar valores de clareza superiores a 15 dB. O mesmo autor afirma que nessas salas existe uma correlação negativa entre tempo de reverberação e clareza para a banda de frequência de oitava de $1.000 \mathrm{~Hz}$.

A classificação de salas vivas (muita reverberação) ou secas (pouca reverberação) acontece através de três parâmetros subjetivos relacionados ao tempo de reverberação: vivacidade (liveness - TR), calor (bass ratio - $\mathrm{BR}$ ) e brilho (brilliance - $\mathrm{Br}$ ) (BERANEK, 1996). Uma sala de concerto é considerada com adequada vivacidade quando o tempo de reverberação médio nas bandas de oitava de 500 e $1.000 \mathrm{~Hz}$ é superior a 1,6 s. O parâmetro calor depende do tempo de reverberação das baixas frequências (bandas de oitava de 125 e 500 $\mathrm{Hz}$ ) quando comparado ao tempo de reverberação das médias frequências $(500$ e $1.000 \mathrm{~Hz})$. Valores ótimos de calor para salas reverberantes com vivacidade superior a 1,8 s estão em torno de $1,1 \mathrm{~s}$ e 1,25 s; e com variações entre $1,1 \mathrm{~s}$ e $1,45 \mathrm{~s}$ para salas com vivacidade igual ou inferior a 1,8 s. O brilho de uma sala pode ser quantificado através da razão entre tempos de reverberação nas médias $(500$ e $1.000 \mathrm{~Hz})$ e nas altas frequências $(2.000 \mathrm{e}$ $4.000 \mathrm{~Hz}$ ). Para que numa sala o som seja claro, vibrante e rico em harmônicos, o brilho deve ser superior a 0,7 (BERANEK, 1996; EVEREST; POHLMANN, 2009).
O fator de força (strength factor - G) está relacionado com a sensação de volume sonoro (loudness), sua quantificação depende do tempo de reverberação e do volume da sala e é expresso em dB (GADE, 2007). Em salas com uma boa qualidade acústica os valores de $\mathrm{G}$ nas frequências médias de 500 e $1.000 \mathrm{~Hz}$ variam entre 4,0 e 5,5 $\mathrm{dB}$, entretanto em salas com diferentes usos, como salas de concerto e casa de ópera, essa faixa pode ter variação maior (BERANEK, 1996; EVEREST; POHLMANN, 2009). Valores de G entre 3 e 10 $\mathrm{dB}$ para salas dedicadas à música de câmara e concertos com volumes superiores a $2.500 \mathrm{~m}^{3}$ também são encontrados (GADE, 2007).

De acordo com critérios de inteligibilidade da fala, o índice de transmissão da fala (speech transmission index - STI) é amplamente utilizado como parâmetro de avaliação acústica de salas onde é indispensável a compreensão de informações transmitidas de forma oral. A determinação do STI é realizada pelo cálculo do fator de redução de modulação, o qual depende do tempo de reverberação, do ruído de fundo e da frequência de modulação da voz, ou seja, o STI leva em consideração o tempo de reverberação, as reflexões tardias e o ruído de fundo das salas, os quais são os principais fatores que afetam a inteligibilidade (LONG, 2011). Esse índice de transmissão da fala consiste em um simples índice: 0 (zero) indica péssima inteligibilidade, e 1 (um) inteligibilidade excelente (INTERNATIONAL..., 2003). O STI é muito prático e um bom primeiro indicador da qualidade do entendimento da fala, porém não pode ser considerado como uma solução para todos os problemas de inteligibilidade da fala (MÜLLER, 2005). No caso das salas de aula de ensino de música a comunicação entre o professor e o aluno deve ser inteligível, e o STI recomendado deve ser superior a 0,75 (excelente) (INTERNATIONAL..., 2003).

\section{Método}

Para caracterizar o comportamento acústico das salas de estudo (SE) e de aula coletiva (SAC) destinadas ao ensino e à prática musical do curso de música foram executadas duas etapas de avaliação. Inicialmente foram determinadas as características geométricas e arquitetônicas das salas de aula, e em conjunto realizou-se uma avaliação qualitativa mediante uma pesquisa de opinião através da aplicação de questionários distribuídos entre alunos e professores do curso de Música para conhecer suas preferências em relação à qualidade acústica das salas. Uma segunda etapa do trabalho consistiu em avaliar o comportamento acústico das salas de aula através de medições, 
sendo adotados os procedimentos da norma ISO 3382-1:2009 (INTERNATIONAL..., 2009).

\section{Avaliação preliminar das características acústicas das salas pelos músicos}

Dois tipos de salas foram avaliados pelos músicos, sendo elas denominadas sala de estudo (SE) e sala de aula coletiva (SAC) (Figura 1). As salas têm formato retangular, com todas as superfícies paralelas. Nessas salas habitualmente estão presentes um piano de cauda ou de parede, cadeiras de madeira, plásticas ou estofadas, armários de madeira ou metálicos, quadro negro ou branco, cortinas blackout ou persianas verticais.

A opinião dos usuários, alunos e professores, foi obtida através de um questionário estruturado, que permitiu conhecer as salas mais utilizadas e as preferências para a prática dos instrumentos musicais. Além disso, pôde-se alcançar maior contato com o vocabulário utilizado por eles para descrever suas sensações em relação ao som percebido nos ambientes. Questões relativas ao isolamento acústico das salas não foram consideradas durante a aplicação do questionário.

O questionário estruturado envolveu dez itens, divididos em três partes. As primeiras duas partes trataram da identificação e da experiência musical, sendo solicitadas informações sobre o instrumento estudado, tempo de estudo com ele, semestre, curso (se bacharelado ou licenciatura) e experiência musical com grupos de apresentação. $\mathrm{Na}$ terceira parte foi requerida a nomeação das três salas melhores e das três piores do ponto de vista acústico, visando obter informações da sensação sonora no interior das salas de música. A última questão, sobre a sala considerada ideal, tinha por objetivo conhecer melhor as necessidades e a linguagem dos músicos para compará-las com as respostas anteriores. As características das salas que foram mais vezes votadas pelos usuários são apresentadas na Tabela 2 .

O tamanho da amostra de sujeitos entrevistados foi determinado assumindo-se uma amostragem probabilística aleatória simples. Como o curso de Música está dividido em bacharelado e licenciatura, com 60 e 52 alunos respectivamente, e 22 professores, somando um total de 134 usuários das salas, o tamanho da amostra foi de 100 elementos.

Os usuários foram abordados no edifício do curso de Música em dias e horários aleatórios, num período de 2 meses. Uma orientação oral de como deveria ser utilizado o questionário e sobre os objetivos do trabalho era dada. Os indivíduos levavam de 5 a 10 min para completar o questionário.

Figura 1 - Salas de ensino e prática musical

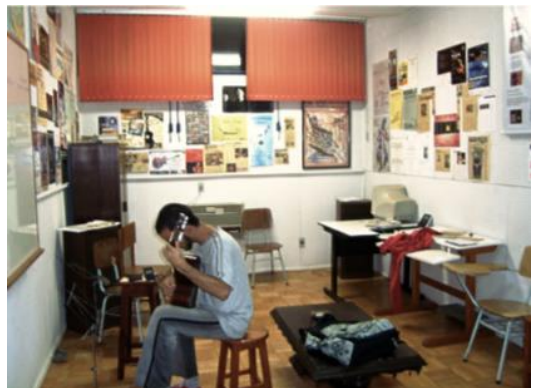

(a) Sala de estudo

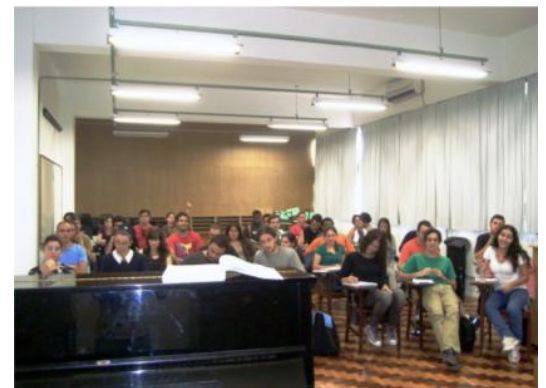

(b) Sala de aula coletiva

Tabela 2 - Distribuição das áreas, volumes e materiais das salas de estudo (SE) e de aula coletiva (SAC) mais votadas pelos músicos

\begin{tabular}{c|c|c|c|c|c|c|c}
\hline Sala & $\begin{array}{c}\text { Área } \\
\text { Piso/Teto } \\
{\left[\mathbf{m}^{\mathbf{2}}\right]}\end{array}$ & $\begin{array}{c}\text { Volume } \\
\mathbf{d e} \mathbf{a r} \\
{\left[\mathbf{m}^{\mathbf{3}}\right]}\end{array}$ & $\begin{array}{c}\text { Altura } \\
{[\mathbf{m}]}\end{array}$ & $\begin{array}{c}\text { Parede de } \\
\text { alvenaria* }^{*} \\
{\left[\mathbf{m}^{\mathbf{2}}\right]}\end{array}$ & $\begin{array}{c}\text { Parede com } \\
\text { absorvedor** } \\
{\left[\mathbf{m}^{\mathbf{2}}\right]}\end{array}$ & $\begin{array}{c}\text { Teto } \\
\text { (forro) }\end{array}$ & $\begin{array}{c}\text { Janela } \\
\text { (vidro) } \\
{\left[\mathbf{m}^{\mathbf{2}}\right]}\end{array}$ \\
\hline SE01 & 27,3 & 79,1 & 2,9 & - & 31,8 & absorvedor $^{* *}$ & 3,0 \\
SE02 & 21,0 & 79,1 & 3,8 & 65,3 & - & concreto $^{* *}$ & 4,8 \\
SE03 & 21,2 & 63,3 & 2,9 & - & 55,2 & absorvedor $^{* *}$ & 2,4 \\
SAC01 & 83,0 & 249,0 & 3,0 & - & 87,7 & absorvedor & 9,4 \\
SAC02 & 43,4 & 162,8 & 3,8 & 87,3 & - & concreto $^{*}$ & 9,8 \\
SAC03 & 87,4 & 327,9 & 3,8 & 112,0 & - & concreto & 19,7 \\
\hline
\end{tabular}

Nota: *Parede simples de alvenaria de tijolos furados, rebocada e pintada, $\mathrm{e}{ }^{* *} \mathrm{O}$ absorvedor sonoro corresponde a placas de papel compensado perfurado. 


\section{Ensaios acústicos}

A resposta impulsiva foi obtida através de medições realizadas de acordo com a norma ISO 3382-1:2009, que descreve os métodos para obtenção dos parâmetros acústicos utilizados para determinar a qualidade acústica de salas em termos de tempo de reverberação e energia para posterior cálculo de clareza, definição e fator de força. As medições acústicas aconteceram nas três salas mais votadas como preferidas pelos músicos e nas três salas consideradas ruins acusticamente.

O sistema de medição permitiu a obtenção da resposta impulsiva e o cálculo dos parâmetros acústicos com o programa Dirac (2008), versão 4.1, (1), instalado em um computador portátil. A reprodução e a aquisição dos sinais sonoros foram realizadas com uma placa de áudio Creative EMU (2), medidor de nível de pressão sonora B\&K 2270 (3), amplificador de potência B\&K 2716 (4) e fonte sonora omnidirecional B\&K $4292 \quad$ (5) (Figura 2).

O sinal de excitação utilizado nas salas foi uma varredura logarítmica (log sweep). Os parâmetros referentes à qualidade acústica das salas foram determinados em bandas de oitava entre $125 \mathrm{~Hz}$ e $4.000 \mathrm{~Hz}$. Para todas as salas utilizaram-se no mínimo duas posições de fonte e quatro de microfone, aumentando esses números de acordo com as dimensões das salas. As recomendações da ISO 3382-1:2009 (INTERNATIONAL..., 2009) foram atendidas para alturas de microfone e de fonte, distância mínima entre fonte e microfone, e repetição das medições em cada ponto.

\section{Análise e discussão dos resultados}

\section{Avaliação preliminar da opinião dos usuários das salas}

Foi preenchido um total de 82 questionários dos 100 distribuídos aos usuários das salas de música. As salas descritas pelos professores e alunos como preferidas e aquelas ruins, bem como a quantidade de vezes em que isso ocorreu, são apresentadas na Figura 3 e nos Quadros 1 e 2. Pode ser observado na Figura 3 que as salas SE02 (35 vezes), SE03 (41 vezes), SAC01 (75 vezes) e SAC02 (42 vezes) foram mais vezes mencionadas como salas ruins, enquanto as salas SE01 (20 vezes) e SAC03 (36 vezes) foram consideradas como as mais preferidas tanto para a prática como para o ensino musical. Estas seis salas foram selecionadas para ser avaliadas através das medições acústicas e assim obter os parâmetros objetivos $\mathrm{T}_{30}$, EDT, BR, TR, $\mathrm{Br}, \mathrm{C}_{80}, \mathrm{D}_{50}, \mathrm{G}$ e STI.

Figura 2 - Equipamentos e esquema de montagem do sistema de medição nas salas de aula

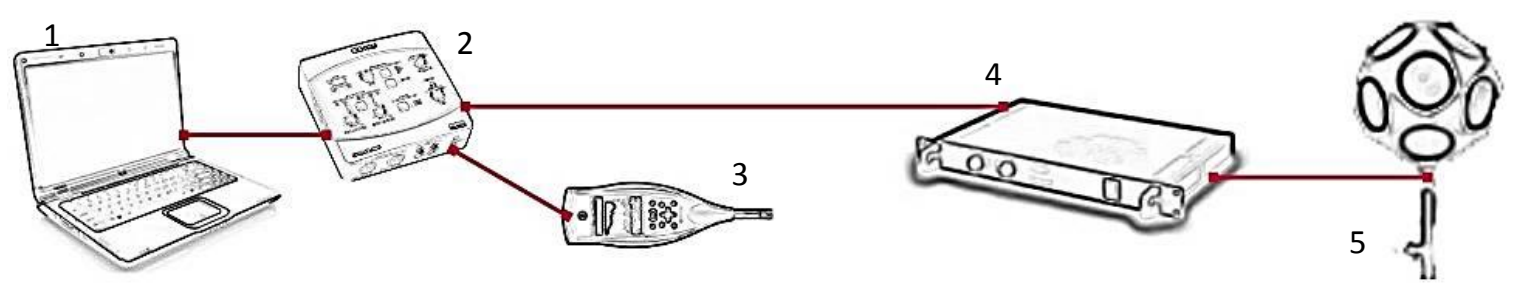

Figura 3 - Número de citações das salas como preferidas e ruins

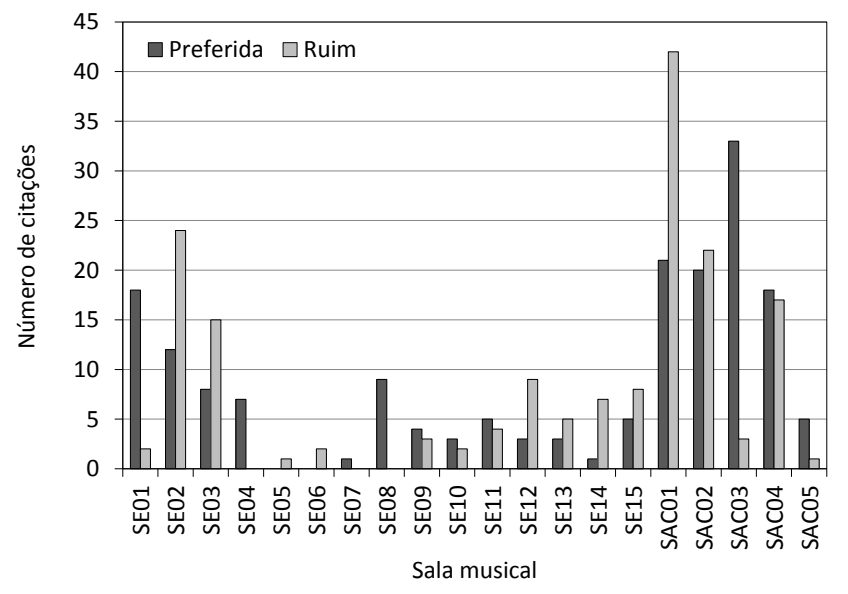

28 Vergara, E. F.; Marros, F.; Paul, S. 
A análise dos questionários possibilitou a identificação de três salas de estudo e de três salas de aula coletiva, as quais foram consideradas boas e ruins pela maioria dos usuários. As características dessas salas na opinião dos usuários são descritas nos Quadros 1 e 2. As opiniões dos músicos estiveram relacionadas principalmente com a reverberação e a projeção sonora produzida pelas salas e pela projeção sonora dos instrumentos musicais. Os músicos concordaram em descrever as salas SE01 e SAC03 como "tendo boa reverberação" ou "reverberação equilibrada" (Quadro 1). Nas descrições do Quadro 2, sobre as salas consideradas ruins, as principais justificativas referem-se às salas SE03 e SAC01 como muito secas ou sem reverberação, e às salas SE02 e SAC02, com reverberação excessiva. De acordo com a Tabela 3, para a sala SAC01 a opinião dos pianistas e violonistas permaneceu dividida, já que as salas foram consideradas acusticamente boas e ruins para a execução desses instrumentos. A sala SE02 foi descrita como reverberante, mas na opinião dos violonistas é percebida tanto como boa quanto como ruim (Tabela 3). A sala SAC02 foi votada tanto como boa quanto como ruim, a opinião dos pianistas ficou dividida, e a totalidade dos cantores a perceberam como uma sala boa.

No questionário os entrevistados também foram solicitados a responder qual era o instrumento que estudavam e quais as salas preferidas e ruins em relação ao instrumento musical executado no local. Os resultados obtidos nesses itens são resumidos na Figura 4. Observa-se que os instrumentos mais citados foram o piano (42 vezes), o violão (40 vezes) e a voz/canto (32 vezes). Vale lembrar que os músicos indicaram mais de um instrumento para cada sala que era utilizada para o ensaio, conforme mostra o resumo da Tabela 3 .

\section{Quadro 1 - Descrição das características acústicas das salas preferidas pelos músicos}

\begin{tabular}{|c|c|}
\hline Sala de estudo SE01 & Sala de aula coletiva $\mathrm{SAC} C \mathrm{~B}$ \\
\hline $\begin{array}{l}\text { - } \quad \text { Tem acústica mais seca } \\
\text { - } \quad \text { Boa reverberação } \\
\text { - } \quad \text { Tea projeção sonora } \\
\text { - } \quad \text { Ajuda a transmitir o som do instrumento } \\
\text { - } \quad \text { Proporciona um som cheio, sem fazer eco } \\
\text { - } \quad \text { Ressoa bem }\end{array}$ & $\begin{array}{ll}\text { - } & \text { Tem reverberação } \\
\text { - } & \text { Boa reverberação } \\
\text { - } & \text { Acústica boa } \\
\text { - } & \text { Boa projeção sonora } \\
\text { - } & \text { Melhor sala para estudo ou recital } \\
\text { - } & \text { Maior ambiência } \\
\text { - } & \text { Reverberação equilibrada } \\
\text { - } & \text { Bom tamanho }\end{array}$ \\
\hline
\end{tabular}

Quadro 2 - Descrição das características acústicas das salas ruins pelos músicos

\begin{tabular}{|c|c|c|c|}
\hline \multicolumn{2}{|c|}{ Sala de estudo } & \multicolumn{2}{|c|}{ Sala de aula coletiva } \\
\hline SE02 & SE03 & SAC01 & SAC02 \\
\hline $\begin{array}{l}\text { - } \quad \text { Muita reverberação } \\
\text { - } \quad \text { Eco } \\
\text { - } \quad \text { Não possui projeção } \\
\text { sonora } \\
\text { - } \quad \text { Ressoa demais } \\
\text { - } \quad \text { O som embola demais } \\
\text { - O som fica mais forte, } \\
\text { prejudica o aluno e engana } \\
\text { - Instrumentos com } \\
\text { maior sonoridade são } \\
\text { prejudicados }\end{array}$ & $\begin{array}{l}\text { - } \quad \text { Não tem } \\
\text { reverberação } \\
\text { - } \quad \text { Muito seca } \\
\text { - } \quad \text { Acústica ruim }\end{array}$ & $\begin{array}{l}\text { - } \quad \text { Pouca/nenhuma } \\
\text { projeção sonora } \\
\text { - Não tem reverberação } \\
\text { - } \quad \text { Acústica seca } \\
\text { - } \quad \text { Acústica ruim } \\
\text { - } \quad \text { Sem harmônicos } \\
\text { - } \quad \text { Som do instrumento } \\
\text { parece menor } \\
\text { - } \quad \text { Sem ambiência, o } \\
\text { instrumento perde potência } \\
\text { e qualidade sonora (timbre) }\end{array}$ & $\begin{array}{l}\text { - } \text { Muita } \\
\text { reverberação } \\
\text { - Muito eco, difícil } \\
\text { perceber a afinação } \\
\text { - Não se entende o } \\
\text { que está sendo } \\
\text { tocado } \\
\text { - Som se propaga } \\
\text { demais }\end{array}$ \\
\hline
\end{tabular}


Figura 4 - Instrumentos musicais estudados pelos músicos

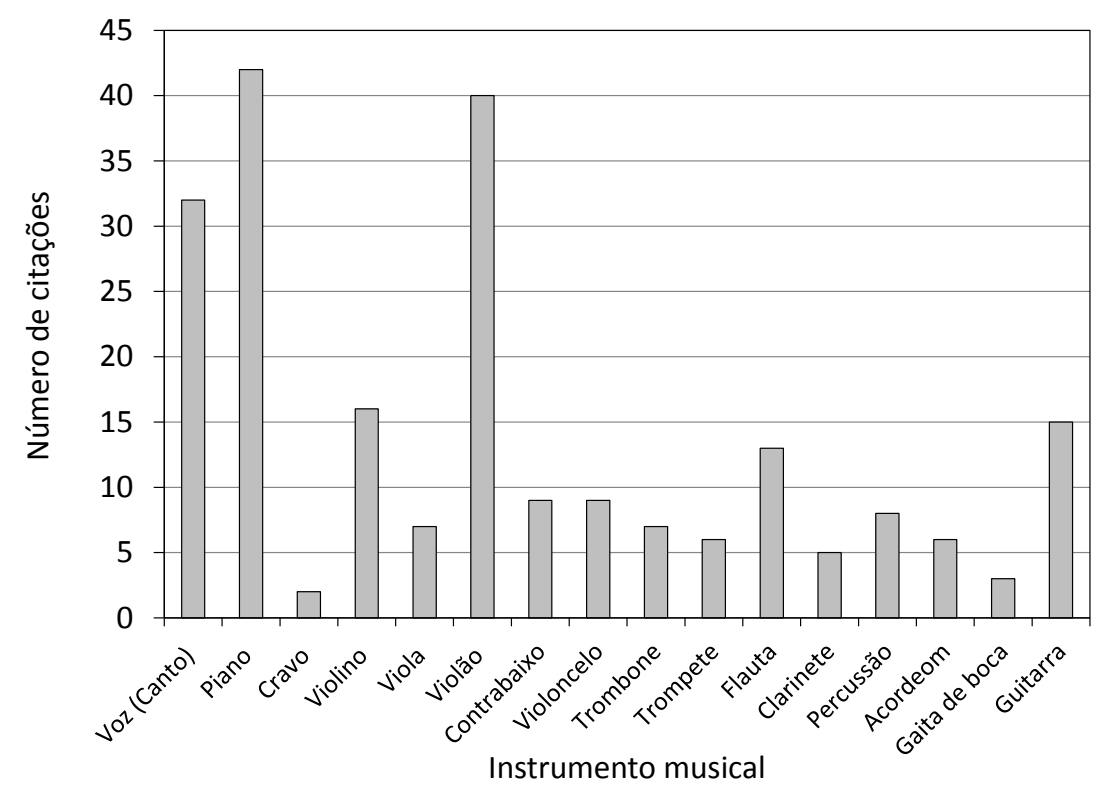

Tabela 3 - Opiniões dos entrevistados sobre a adequação das salas selecionadas (de estudo e de aula coletiva) para os diferentes instrumentos musicais

\begin{tabular}{|c|c|c|c|c|c|c|c|c|c|c|c|c|c|}
\hline \multirow{2}{*}{$\begin{array}{c}\text { Instrumento } \\
\text { musical }\end{array}$} & \multicolumn{2}{|c|}{ SE01 } & \multicolumn{2}{|c|}{ SE02 } & \multicolumn{2}{|c|}{ SE03 } & \multicolumn{2}{|c|}{ SAC01 } & \multicolumn{2}{|c|}{ SAC02 } & \multicolumn{2}{|c|}{ SAC03 } & \multirow{2}{*}{ Total } \\
\hline & Boa & Ruim & Boa & Ruim & Boa & Ruim & Boa & Ruim & Boa & Ruim & Boa & Ruim & \\
\hline Voz (Canto) & - & - & 1 & 2 & - & 6 & - & 9 & 6 & - & 7 & 1 & 32 \\
\hline Piano & 6 & 1 & - & 6 & - & 1 & 5 & 7 & 4 & 5 & 5 & 2 & 42 \\
\hline Cravo & - & - & - & - & - & - & 1 & - & - & - & 1 & - & 2 \\
\hline Violino & - & - & 2 & 1 & - & 2 & - & 4 & 1 & 1 & 5 & - & 16 \\
\hline Viola & 1 & - & 1 & 1 & 1 & - & - & 2 & - & - & 1 & - & 7 \\
\hline Violão & 3 & - & 5 & 5 & - & 3 & 6 & 6 & 5 & 3 & 4 & - & 40 \\
\hline Contrabaixo & 2 & - & - & 2 & - & - & 2 & 1 & - & 1 & 1 & - & 9 \\
\hline Violoncelo & 1 & - & - & 1 & 1 & - & - & 2 & - & 3 & 1 & - & 9 \\
\hline Trombone & 1 & - & - & 2 & 2 & - & - & - & - & 2 & - & - & 7 \\
\hline Trompete & - & - & - & 1 & 1 & 1 & 1 & 1 & - & 1 & - & - & 6 \\
\hline Flauta & 2 & - & - & 2 & - & - & 1 & 3 & 1 & 1 & 3 & - & 13 \\
\hline Clarinete & 1 & - & 1 & - & 1 & - & - & 1 & - & 1 & - & - & 5 \\
\hline Percussão & - & - & - & - & 1 & 1 & - & 3 & - & 1 & 2 & - & 8 \\
\hline Acordeom & - & - & 1 & - & - & - & 1 & 1 & 2 & 1 & - & - & 6 \\
\hline $\begin{array}{l}\text { Gaita de } \\
\text { boca }\end{array}$ & 1 & - & 1 & - & - & - & - & 1 & - & - & - & - & 3 \\
\hline Guitarra & - & 1 & - & 1 & 1 & 1 & 4 & 1 & 1 & 2 & 3 & - & 15 \\
\hline Total & 18 & 2 & 12 & 24 & 8 & 15 & 21 & 42 & 20 & 22 & 33 & 3 & \\
\hline
\end{tabular}

A distribuição das opiniões dos músicos das seis salas mais votadas em função do instrumento musical executado na sala é apresentada na Tabela 3. As salas musicais mais citadas como preferidas foram a SE01 e a SAC03, e as menções negativas somaram para essas salas menos de $3 \%$ da totalidade de citações. A sala SE02 recebeu 24 menções negativas e 12 positivas, sendo considerada ruim para a execução do piano, mas as preferências para o violão ficaram empatadas. A sala SE03 teve 15 menções negativas, as quais procedem dos músicos que executam violão e canto (voz). A sala SAC01 foi a mais citada como ruim pela maioria dos músicos, com um total de 42 menções, e a voz e o violino contribuíram com 9 e 4 citações negativas respectivamente. A mesma sala SAC01 foi considerada boa e ruim pelos músicos que executam violão e piano. Cabe notar que quatro dos cinco guitarristas entrevistados opinaram que a sala SA01 é boa. A sala SAC02 foi votada como ruim, com 22 citações, e também teve 20 menções positivas, o que ocasionou

30 Vergara, E. F.; Marros, F.; Paul, S. 
praticamente empate de opiniões, sendo estudantes de canto os únicos que fizeram menções positivas para esta sala, com 6 citações; a opinião dos pianistas e violonistas ficou dividida. A sala SAC02 é comentada como um ambiente reverberante e de difícil entendimento do que se toca nele. As opiniões dos músicos a respeito das salas SAC01 e SAC02 indicam que existem outros fatores que podem afetar a qualidade sonora desses ambientes musicais, como a variação da radiação sonora dos instrumentos de música, conforme afirmam Benade (1985) e Osman (2010). Outro fator que pode interferir na qualidade sonora é a capacidade do ouvinte em localizar a fonte (instrumento musical) dentro de uma sala devido às diferenças de tempo e de amplitude interaurais entre as orelhas do músico e a interferência dos modos acústicos da sala (BENADE, 1985).

\section{Parâmetros acústicos das salas}

A seguir são apresentados os resultados da medição dos parâmetros $\mathrm{T}_{30}$, EDT, BR, TR, Br, $\mathrm{C}_{80}, \mathrm{D}_{50}, \mathrm{G}$ e STI por bandas de frequência de oitava na faixa de 125 a $4.000 \mathrm{~Hz}$, utilizados para avaliação da qualidade acústica das três salas de estudo e das três salas de aula coletiva.

A Figura 5 mostra os resultados médios obtidos para o tempo de reverberação $\left(\mathrm{T}_{30}\right)$. $\mathrm{O}$ grupo de salas SE01, SE03 e SAC01 apresentaram valores de $\mathrm{T}_{30}$ entre $0,2 \mathrm{~s}$ e $0,6 \mathrm{~s}$ nas faixas de frequências de 125 a $4.000 \mathrm{~Hz}$. As superfícies internas (paredes e teto) dessas salas possuíam tratamento acústico com material absorvedor sonoro perfurado, com exceção das paredes da sala SE01, que tinham algumas de suas superfícies cobertas com placas de gesso acartonado e chapas de madeira em MDF. Os volumes de ar de cada sala eram 79,1 $\mathrm{m}^{3}$ (SE01), 63,3 $\mathrm{m}^{3}$ (SE03) e $249 \mathrm{~m}^{3}$ (SAC01). De acordo com a opinião dos músicos, as três salas foram percebidas como secas, no entanto as salas
SE03 e SAC01 foram consideradas ruins pelos músicos, e a sala SE01 foi mencionada como a preferida por grande parte dos entrevistados, sendo considerada com reverberação boa ou equilibrada.

Ainda analisando a Figura 5, o grupo de salas SE02, SAC02 e SAC03 apresentaram $\mathrm{T}_{30}$ entre $1 \mathrm{~s}$ e $2,6 \mathrm{~s}$, na faixa entre 125 e $4.000 \mathrm{~Hz}$, e as curvas do tempo de reverberação apresentaram tendência a decair com o aumento da frequência. Os volumes dessas salas são bastante distintos, com valores respectivos de 79,1, 162,8 e 327,9 $\mathrm{m}^{3}$. As superfícies internas delas não tinham tratamento acústico com absorvedores sonoros, a não ser na sala SAC03, que possuía uma parede coberta com chapas de madeira em MDF. Essas salas também receberam uma descrição similar dos músicos, que as consideraram salas reverberantes, porém a reverberação na sala $\mathrm{SAC03}$ foi apontada como boa e equilibrada, enquanto as salas SE02 e SAC02 foram percebidas com reverberação excessiva.

Os dados da média do tempo de decaimento inicial (EDT) em cada banda de frequência das salas avaliadas são apresentados na Figura 6 . Considerando que o EDT está relacionado à percepção da reverberação, observa-se que esse parâmetro agrupa os seis ambientes em salas secas (SE01, SE03 e SAC01) e reverberantes (SE02, SAC02 e SAC03), o que corrobora os resultados obtidos na medição dos tempos de reverberação (Figura 5) e a opinião dos entrevistados (Quadros 1 e 2). Os valores de EDT da Figura 6 são representativos da média em relação aos pontos de medição no interior de cada uma das seis salas avaliadas. Os maiores desvios padrão observados permaneceram em média entre $0,1 \mathrm{~s}$ e $0,2 \mathrm{~s}$ para as bandas de frequência de oitava de 125 e $250 \mathrm{~Hz}$, sendo para as bandas entre 500 e $4.000 \mathrm{~Hz}$ os desvios inferiores a $0,1 \mathrm{~s}$.

Figura 5 - Tempos de reverberação $\left(\mathrm{T}_{30}\right)$ das salas de estudo (SE) e de aula coletiva (SAC)

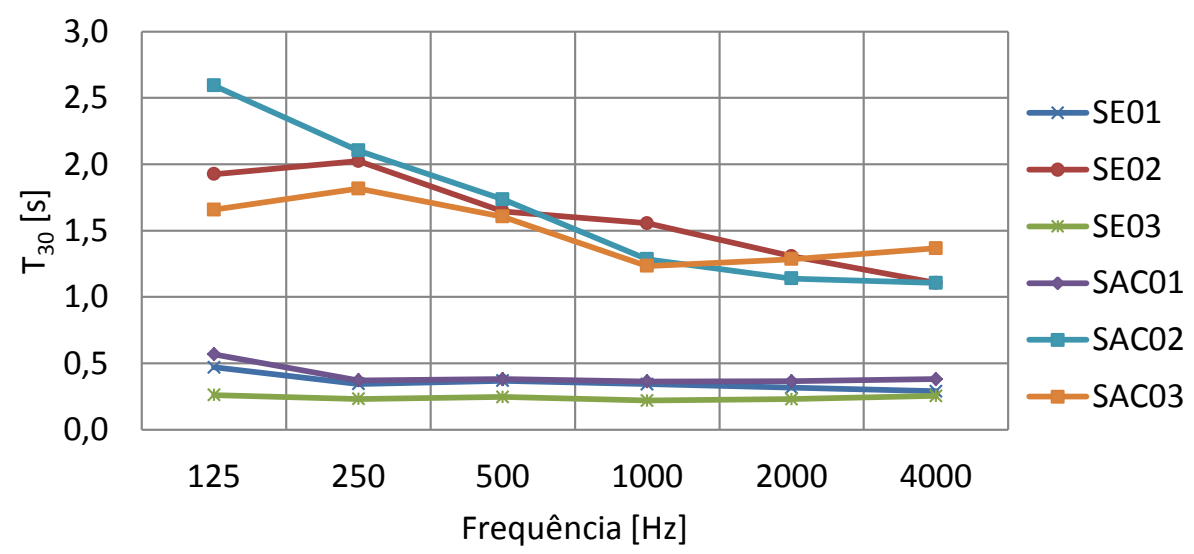


Figura 6 - Tempos de decaimento inicial (EDT) das salas de estudo e de aula coletiva

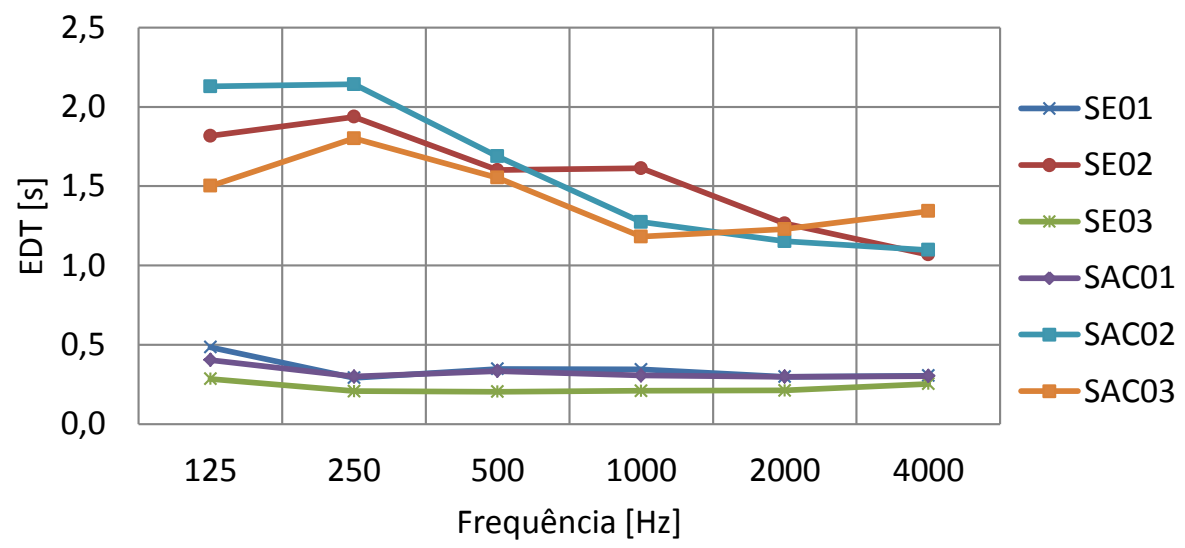

A Tabela 4 mostra os resultados obtidos para os parâmetros calor (BR), vivacidade (TR) e brilho (Br). Os valores do calor para a maioria das salas avaliadas foram menores que 1,8 e variaram entre 1,1 e 1,6, o que indica que os valores de tempo reverberação nas bandas das baixas frequências são apropriados para salas de concerto, conforme menciona Beranek (1996). As salas mais secas foram as SE01 e SE03, que mostraram os menores valores de calor. No caso da vivacidade, as salas SE02, SAC02 e SAC03 podem ser consideradas vivas porque apresentaram valores próximos de 1,6 s. Além disso, as salas SE01, SE03 e SAC01 são categorizadas como secas porque a vivacidade foi menor que $0,4 \mathrm{~s}$. Para o brilho, a maioria das salas pode ser considerada apropriada nas altas frequências, já que superaram o valor 0,7 , recomendado segundo apontam Beranek (1996) e Everest e Pohlmann (2009), caracterizando as salas SE02 e SAC02 como menos brilhosas ou mais secas. Levando em consideração as opiniões dos músicos, percebe-se que o parâmetro mais bem relacionado à opinião dos músicos foi a vivacidade.

Os resultados apresentados nas Figuras 7 e 8 referem-se à clareza e à definição respectivamente. A clareza $\left(\mathrm{C}_{80}\right)$ para as salas SE01, SAC01 e SE03 variou pouco nas bandas com frequência central superior a $250 \mathrm{~Hz}$, estando próximo a 15 e $21 \mathrm{~dB}$, o que mostra que essas salas têm baixo grau de distinção das notas musicais. Os valores de clareza confirmam os resultados obtidos por Cabrera (2007) para salas de prática musical com volumes entre 10 e $100 \mathrm{~m}^{3}$. Ademais, os músicos classificaram essas salas como sem reverberação e secas. As salas SE01, SAC01 e SE03 apresentam tempos de reverberação inferiores a 0,6 s.

Para as salas SE02, SAC02 e SAC03, os valores de $\mathrm{C}_{80}$ estão entre $-3,0 \mathrm{a}+5,2 \mathrm{~dB}$, o que mostra que a clareza está dentro da faixa aceitável $(-4 \mathrm{a}+5 \mathrm{~dB}$, de acordo com Beranek (1996), e -2 a $+4 \mathrm{~dB}$ conforme Meyer (2009)). Contudo, e de acordo com a opinião dos músicos, as salas SE02 e SAC02 foram consideradas muito reverberantes, e alguns entrevistados descreveram o som da sala SE02 como embolado (Quadro 2).

Na Figura 8 a definição $\left(D_{50}\right)$, em média, na faixa entre 250 e $4.000 \mathrm{~Hz}$ das salas SE01, SE03 e SAC01 se aproximou de 92\%. Assim, essas salas refletem boa qualidade acústica para o uso da palavra falada, já que a definição foi superior a $65 \%$ nas bandas de 500 e $1.000 \mathrm{~Hz}$. Por outro lado, para as salas SE02, SAC02 e $\mathrm{SAC03}$ esse parâmetro variou ao redor de $41 \%$, classificandoas como pouco adequadas para a fala. Na descrição dos músicos, as salas SE01, SE03 e SAC01 são consideradas secas (sem reverberação), e as salas SE02, SAC02 e SAC03, reverberantes.

Como pode ser observado na Figura 9, a sala SAC01 apresentou o menor valor de fator de força (G) entre as seis salas, variando em torno dos 17 $\mathrm{dB}$, na faixa dos 125 a $4.000 \mathrm{~Hz}$. Essa sala foi julgada pelos músicos como muito seca e sem projeção sonora. A sala de estudo SE02 foi a que alcançou o maior valor de $\mathrm{G}$, próximo dos $28 \mathrm{~dB}$, e foi descrita sem projeção sonora e muito reverberante. As salas SE01, SE03 e SAC03 apresentaram valores próximos aos $20 \mathrm{~dB}$ para o parâmetro $\mathrm{G}$, com variações menores que $1 \mathrm{~dB}$ na faixa de frequência entre 125 e $4.000 \mathrm{~Hz}$. As salas SE01 e SE03 têm tempos de reverberação parecidos, e a sala SE01 é considerada seca pelos músicos (Quadro 1). As salas SE01 e SAC03 foram os ambientes preferidos pelos músicos, descritos com boa projeção sonora. Cabe salientar que os valores de $\mathrm{G}$ obtidos para as salas de estudo e de aula coletiva permaneceram acima dos valores recomendados (3 a $10 \mathrm{~dB}$ ) para salas de música de câmara e concerto com volumes superiores a 2.500 $\mathrm{m}^{3}$. 
Tabela 4 - Valores do calor (BR), vivacidade (TR) e brilho $(\mathrm{Br})$ das salas de estudo e de aula coletiva

\begin{tabular}{l|c|c|c}
\hline Sala & Calor (BR) & $\begin{array}{c}\text { Vivacidade (TR) } \\
{[\mathbf{s}]}\end{array}$ & Brilho $(\mathbf{B r})$ \\
\hline SE01 & 1,1 & 0,4 & 0,9 \\
SE02 & 1,2 & 1,6 & 0,8 \\
SE03 & 1,1 & 0,2 & 1,0 \\
SAC01 & 1,3 & 0,4 & 1,0 \\
SAC02 & 1,6 & 1,6 & 0,7 \\
SAC03 & 1,2 & 1,4 & 0,9 \\
\hline
\end{tabular}

Figura 7 - Clareza $\left(C_{80}\right)$ das salas de estudo e de aula coletiva

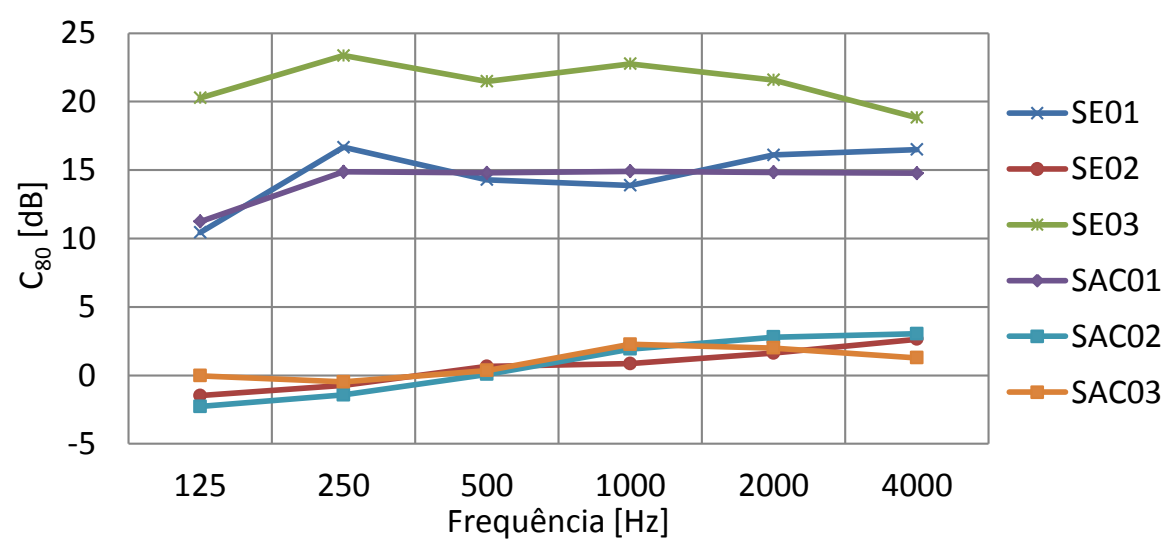

Figura 8 - Definição (D50) das salas de estudo e de aula coletiva

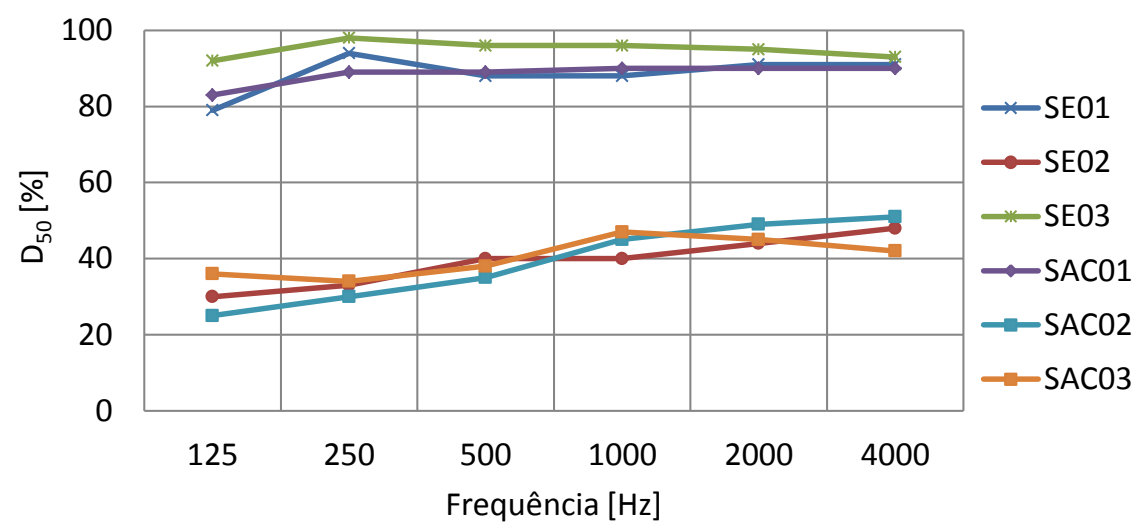

Figura 9 - Fator de força (G) das salas de estudo e de aula coletiva

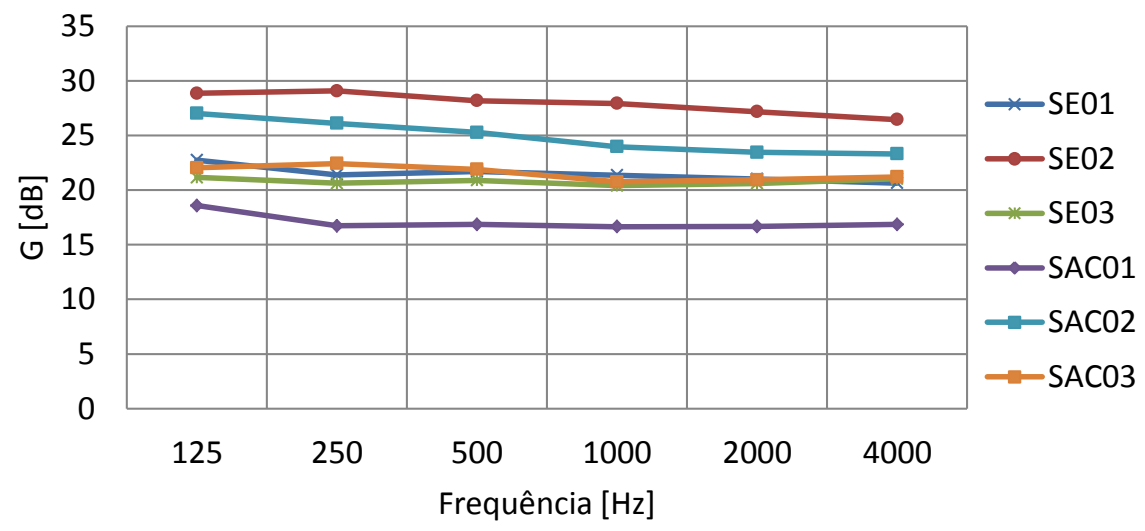


A Tabela 5 apresenta os valores de STI obtidos para as seis salas estudadas, confrontados com os valores da norma IEC 60268-16 (INTERNATIONAL..., 2003). É possível observar nessa tabela que as salas encontram-se dentro dos padrões exigidos pela norma, pois as salas SE01, SE03 e SAC01 apresentaram valores de STI compreendidos dentro da faixa considerada excelente $(0,75-1,00)$ para a fala. Para as salas SE02, SAC02 e SAC03, os valores de STI estão dentro da faixa considerada adequada $(0,45-0,60)$, ou seja, as seis salas avaliadas apresentaram condições apropriadas para a transmissão sonora da palavra falada se o STI for o único parâmetro de análise.

\section{Considerações a respeito das salas estudadas}

A Tabela 6 apresenta uma síntese das principais características das salas e dos dados obtidos da média dos parâmetros utilizados para a avaliação da qualidade acústica nas bandas de frequência de oitava de 500 e $1.000 \mathrm{~Hz}$.

As salas SE01, SE03 e SAC01 possuíam aplicação de tratamento acústico nas paredes e apresentaram valores próximos para a maioria dos parâmetros acústicos quantificados. Os tempos de reverberação $\left(\mathrm{T}_{30}\right)$ e de decaimento inicial (EDT) desses recintos variaram em torno de $0,3 \mathrm{~s}$. A clareza $\left(\mathrm{C}_{80}\right)$ apresentou valores bastante elevados, variando de 14 a $22 \mathrm{~dB}$, e a definição $\left(\mathrm{D}_{50}\right)$ alcançou valores acima de $88 \%$. Isso permite confirmar que esses valores representam uma boa adequação para salas destinadas à fala. Entre essas salas somente a SE01 foi considerada preferida pelos músicos, e a principal descrição foi que ela tem boa reverberação e boa projeção sonora. As salas SE03 e SAC01 foram consideradas muito secas, sendo a sala SAC01 descrita também como sem projeção sonora.

As salas $\mathrm{SE02}$, SAC02 e SAC03 tiveram como característica a ausência de tratamento acústico e foram consideradas reverberantes pelos músicos. Os tempos $\mathrm{T}_{30}$ e EDT medidos permaneceram em média próximos de $1,5 \mathrm{~s}$. $\mathrm{O} \mathrm{C}_{80}$ teve valores baixos, de $1 \mathrm{~dB}$, e o $\mathrm{D}_{50}$ não superou os $43 \%$. Contudo, somente a sala $\mathrm{SAC03}$ foi considerada preferida pela grande maioria dos músicos, com avaliação de reverberação boa e equilibrada. Para a sala SAC02 as opiniões ficaram divididas entre reverberação boa e excessiva, enquanto a sala SE02 foi considerada muito reverberante.

Tabela 5 - Índice de transmissão da fala (STI) das salas de estudo e de aula coletiva

\begin{tabular}{l|c|l}
\hline \multicolumn{1}{c|}{ Sala } & STI & \multicolumn{1}{c}{$\begin{array}{c}\text { Referência } \\
\text { IEC 60268-16 }\end{array}$} \\
\hline SE01 & $0,82 \pm 0,01$ & Excelente $(0,75-1,00)$ \\
SE02 & $0,54 \pm 0,00$ & Adequado $(0,45-0,60)$ \\
SE03 & $0,87 \pm 0,01$ & Excelente $(0,75-1,00)$ \\
SAC01 & $0,83 \pm 0,02$ & Excelente $(0,75-1,00)$ \\
SAC02 & $0,55 \pm 0,01$ & Adequado $(0,45-0,60)$ \\
SAC03 & $0,53 \pm 0,03$ & Adequado $(0,45-0,60)$ \\
\hline
\end{tabular}

Tabela 6 - Síntese das características acústicas das salas avaliadas, com valores médios de 500 e 1.000 $\mathrm{Hz}$

\begin{tabular}{l|c|l|c|c|c|c|c}
\hline Sala & $\begin{array}{c}\text { Tratamento } \\
\text { acústico }\end{array}$ & \multicolumn{1}{|c|}{ Opinião dos músicos } & $\begin{array}{c}\mathbf{T}_{\mathbf{3 0}} \\
{[\mathbf{s}]}\end{array}$ & $\begin{array}{c}\mathbf{E D T} \\
{[\mathbf{s}]}\end{array}$ & $\begin{array}{c}\mathbf{C}_{\mathbf{8 0}} \\
{[\mathbf{d B}]}\end{array}$ & $\begin{array}{c}\mathbf{D}_{\mathbf{5 0}} \\
{[\mathbf{\%}]}\end{array}$ & $\begin{array}{c}\mathbf{G} \\
{[\mathbf{d B}]}\end{array}$ \\
\hline SE01 & Sim & Seca, adequada & 0,4 & 0,3 & 14 & 88 & 22 \\
\hline SE03 & Sim & Seca, inadequada & 0,2 & 0,2 & 22 & 96 & 21 \\
\hline SAC01 & Sim & Seca, inadequada & 0,4 & 0,3 & 15 & 90 & 17 \\
\hline SE02 & Não & Reverberante, inadequada & 1,6 & 1,6 & 1 & 40 & 28 \\
\hline SAC02 & Não & Reverberante, inadequada & 1,5 & 1,5 & 1 & 40 & 25 \\
\hline SAC03 & Não & Reverberante, adequada & 1,4 & 1,4 & 1 & 43 & 21 \\
\hline
\end{tabular}


As salas SE01 e SAC01 apresentaram valores muito próximos para os parâmetros $\mathrm{T}_{30}$, EDT, $\mathrm{D}_{50}$ e $\mathrm{C}_{80}$, sendo o fator de força $\mathrm{G}$ de $22 \mathrm{~dB}$ e $17 \mathrm{~dB}$ para as salas SE01 e SAC01 respectivamente. Vale lembrar que o volume da sala SE01 é de $79,1 \mathrm{~m}^{3}$ e que o da sala SAC01 é de $249 \mathrm{~m}^{3}$. Na opinião dos músicos, ambas salas são secas, entretanto a sala SE01 é boa para os pianistas e violonistas, e a sala SAC01 é ruim para os cantores e violinistas. A sala de estudo SE01 parece ser preferida pelos músicos porque nela a potência sonora dos instrumentos é superior ( $\mathrm{G}$ igual a $22 \mathrm{~dB}$ ) em relação à sala de aula coletiva $\mathrm{SAC01}$. Isso confirma o que Benade (1985) e Osman (2010) apontam como um dos fatores que interferem na qualidade do ambiente musical relativo à variação da radiação sonora dos instrumentos nesses ambientes.

A partir da análise dos dados obtidos nas medições e da avaliação qualitativa das salas de estudo e de aula coletiva para ensino de música, infere-se que salas de prática e estudo musical individual com volume em torno de $80 \mathrm{~m}^{3}$ e com tempo de reverberação próximo dos $0,4 \mathrm{~s}$ podem ser consideradas adequadas e preferidas pelos músicos, informação confirmada para esse tipo de sala pelas pesquisas desenvolvidas por Lane e Mikeska (1955), Karsai (1974), Lamberty (1980), Nagata (1989), Cohen (1992), Teuber e Vöelker (1993) e Lokki e Salmensaari (2007). Uma clareza de aproximadamente $14 \mathrm{~dB}$ para esse tipo de sala individual pode ser recomendada, o que é verificado pelo estudo de Cabrera (2007) para salas de audição e sala de prática musical com volumes entre 80 e $100 \mathrm{~m}^{3}$. Por outro lado, uma sala de aula coletiva com volume em torno de 330 $\mathrm{m}^{3}$ com tempo de reverberação de $1,5 \mathrm{~s}$, clareza de $1 \mathrm{~dB}$ e fator de força de $21 \mathrm{~dB}$ é preferida como reverberante pelos músicos.

\section{Conclusões}

Os resultados deste estudo, no qual foram caracterizadas acusticamente três salas de estudo e três salas de aula coletiva de um curso de graduação de uma universidade, verificam que existiu dificuldade por parte dos músicos para expressar suas percepções a respeito da acústica das salas, bem como certa confusão na aplicação dos conceitos de condicionamento acústico e de isolamento acústico. A principal descrição de suas percepções do som dentro dos recintos foi em termos da reverberação do local e da projeção sonora do instrumento musical. Assim, as salas consideradas preferidas foram avaliadas como tendo reverberação boa ou equilibrada, e as salas consideradas ruins foram julgadas como sem reverberação ou reverberação excessiva.
Os resultados das medições acústicas confirmaram a opinião dos músicos em relação aos tempos de reverberação determinados experimentalmente. As salas consideradas ruins e descritas como secas apresentaram tempos de reverberação (500-1.000 $\mathrm{Hz}$ ) muito baixos, em torno de $0,3 \mathrm{~s}$, e as salas assinaladas com reverberação excessiva tiveram tempos de reverberação em torno de $1,5 \mathrm{~s}$, o que, para uma sala de volume reduzido, pode ser considerado muito alto. Por outro lado, a preferência dos músicos por salas consideradas secas ou reverberantes também deve considerar outros fatores além do tempo de reverberação, como, por exemplo, a clareza e o fator de força, os quais indicarão, em ambientes fechados, aspectos da nitidez do som e da potência sonora dos instrumentos musicais respectivamente.

Considerando o procedimento experimental aplicado para a obtenção dos parâmetros acústicos objetivos, a maioria das salas aqui estudadas apresentou deficiências em relação ao condicionamento acústico para o desenvolvimento de atividades musicais em ambientes com apropriada qualidade acústica. Além disso, somente duas das seis salas foram consideradas pela grande maioria dos músicos como adequadas, sem receber críticas negativas consideráveis, para a prática e ensino musical. Uma dessas salas preferidas pelos músicos foi uma sala de estudo individual com volume em torno de $80 \mathrm{~m}^{3}$ e com tempo de reverberação de $0,4 \mathrm{~s}$, e foi descrita como seca pelos músicos. A outra sala preferida foi uma sala de estudo de aula coletiva com volume em torno de $330 \mathrm{~m}^{3}$, tempo de reverberação de 1,4 s e caracterizada como reverberante pelos músicos. Os resultados deste estudo permitiram relacionar os parâmetros acústicos objetivos (tempo de reverberação, EDT, clareza e definição), determinados experimentalmente nas salas de aula de estudo e de aula coletiva, com os resultados da avaliação qualitativa feita pelos músicos usuários dessas salas.

\section{Referências}

\author{
AMERICAN NATIONAL STANDARDS \\ INSTITUTE. ANSI S12.60-2002: acoustical \\ performance criteria, design requirements, and \\ guidelines for schools. Melville, 2002.
}

BARRON, M. Auditorium Acoustics and Architectural Design. $2^{\text {nd }}$. ed. New York: Spon Press, 2010.

BENADE, A.H. From Instrument to Ear in a Room: direct or via recording. Journal of the Audio Engineering Society, v. 33, n. 4, p. 218233, 1985. 
BERANEK, L. Concert and Opera Halls: how they sound. New York: Acoustical Society of America, 1996.

BERANEK, L. Subjective Rank-Orderings and Acoustical Measurements for Fifty-Eight Concert Halls. Acta Acustica United With Acustica, v. 89, p. 494-508, 2003.

BRADLEY, J. Review of Objective Room Acoustics Measures and Future Needs. Applied Acoustics, v. 72, n. 10, p. 713-720, 2011.

BRASIL. Lei de Diretrizes e Bases da Educação Nacional. Lei $n^{\circ}$ 9.394/96, de 20 de dezembro de 1996.

BRASIL. Lei no 11.769, de 18 de agosto de 2008 . Altera a Lei no 9.394, de 20 de dezembro de 1996, Lei de Diretrizes e Bases da Educação, para dispor sobre a obrigatoriedade do ensino da música na educação básica.

BUILDING BULLETIN 93. Acoustic Design of Schools: draft of Building Bulletin 93 for consultation, including the specification of acoustic performance to comply with the Building Regulations. Great Britain. Department for Education and Skills. Schools Building and Design Unit, corp creator, 2002.

BUILDING BULLETIN 93. Acoustic, design of schools: a design guide. London: Department for Education and Skills, 2003.

CABRERA, D. Acoustic Clarity and Auditory Room Size Perception. In: INTERNATIONAL CONGRESS ON SOUND AND VIBRATION, 14., Cairns, 2007. Proceedings... Cairns: ICSV, 2007.

COHEN, E. Acoustics of Practice Rooms. In: AUDIO ENGINEERING SOCIETY CONVENTION, 92., Wien, 1992. Proceedings... Wien: AES, 1992.

DIRAC Acoustics Measurement Software, versão 4.1. Brüel \& Kæjer, Acoustics Engineering, Manual, 2008.

EVEREST, F. A.; POHLMANN, K. C. Master Handbook of Acoustics. $5^{\text {th }}$. ed. New York: McGraw-Hill, 2009.

FIGUEIREDO, F. L. Parâmetros Acústicos Subjetivos: critérios para avaliação da Qualidade acústica de salas de música. São Paulo, 2005. 259 f. Dissertação (Mestrado em Musicologia) -Escola de Música, Universidade de São Paulo, São Paulo, 2005.

GADE, A. C. Acoustics in Halls for Speech and Music. In: ROSSING, T. D. (Ed.). Handbook of acoustics. New York: Springer Science+Business Media, 2007.
HATLEVIK, E. Are Musicians Affected by Room Acoustics in Rehearsal Rooms?

Trondheim, 2012. $90 \mathrm{f}$. Thesis (Master of Science in Electronics) - Norwegian University of Science and Technology, Trondheim, 2012.

IAZZETTA, F. et al. AcMus: computational tools for measurement, analysis and simulation of room acoustics. In: CONGRESSO IBEROAMERICANO DE ACÚSTICA, 4., Guimarães, 2004. Anais... Guimarães: FIA2004, 2004.

INTERNATIONAL ELECTROTECHNICAL COMMISSION. IEC 60268-16: sound system equipment: part 16: objective rating of speech intelligibility by speech transmission index. Switzerland, 2003.

INTERNATIONAL ORGANIZATION FOR STANDARDIZATION. ISO 3382-1: acoustics: measurement of room acoustic parameters: part 1: performance spaces. Switzerland, 2009.

KARSAI, M. The Acoustical Reconstruction of teaching Studios at the Hungarian Academy of Music. In: INTERNATIONAL CONGRESS ON ACOUSTICS, 8., London, 1974. Anais... London: ICA, 1974.

KOSKINEN, H.; TOPPILA, E.; OLKINUORA, P. Facilities for Music Education and Their Acoustical Design. International Journal of Occupational Safety and Ergonomics, v. 16, n. 1, p. 93-104, 2010.

KUTTRUFF, H. Room Acoustics. $5^{\text {th }}$. ed. New York: Spon, 2009.

LAMBERTY, D. C. Music Practice Rooms. Journal of Sound and Vibration, v. 69, n. 1, p. 149-155, 1980.

LANE, R. N.; MIKESKA, E. E. Study of Acoustical, Requirements for Teaching Studios and Practice Rooms in Music School Buildings. Journal of the Acoustical Society of America, v. 27, n. 6, p. 1087, 1955.

LOKKI, T.; SALMENSAARI, O. Report No 71119-1, Measurement Report: teaching facilities of Espoo Music Institute. Helsinki, 2007.

LOKKI, T. Tasting Music Like Wine: sensory evaluation of concert halls. Physics Today, v. 67, n. 1, p. 27-32, 2014.

LONG, M. Architectural Acoustics. $2^{\text {nd }}$. ed. London: Elsevier, 2011.

MEYER, J. Acoustics and the Performance of Music: manual for acousticians, audio engineers, musicians, architects and musical instruments makers. 5. ed. Berlin: Springer, 2009. 
MULLER, S. Medir o STI. In: SEMINÁRIO DE MÚSICA, CIÊNCIA E TECNOLOGIA, 2., São Paulo, 2005. Anais... São Paulo, 2005.

NAGATA, M. Nankohall. In: MCCUE, E.; TALASKE, R. H. Acoustical design of music education facilities. Syracuse, New York, 1989.

OSMAN, R. Designing Small Music Practice Rooms for Sound Quality. In: INTERNATIONAL CONGRESS ON ACOUSTICS, 20, Sydney, 2010. Proceedings... Sydney: ICA, 2010.

RYHERD, E. Acoustic Design of Music Rehearsal Rooms. Physics Today, v. 61, n. 8, p. 68-69, 2008.

TEUBER, W.; VÖELKER E-J. Acoustical Requirements and Results for Music Rehearsal Rooms. In: AUDIO ENGINEERING SOCIETY CONVENTION, 94., Berlin, 1993. Proceedings... Berlin: AES, 1993.
VORLÄNDER, M.; SUMMERS, J. Auralization: fundamentals of acoustics, modelling, simulation, algorithms, and acoustic virtual reality. Berlin: Springer, 2008.

\section{Agradecimentos}

Os autores agradecem a participação e colaboração dos músicos (professores e alunos) do curso de Música da Universidade Federal de Santa Maria (UFSM) que contribuíram com as opiniões e respostas nas entrevistas aplicadas durante a pesquisa. Também, manisfestamos nossos agradecimentos ao curso de Engenharia Acústica da UFSM, pela colaboração com o empréstimo de equipamentos para realizar as medições acústicas deste estudo. Agradecemos à Coordenação de Aperfeiçoamento de Pessoal de Ensino Superior (Capes) pela concessão de bolsa de estudo.

\section{Erasmo Felipe Vergara}

Laboratório de Vibrações e Acústica, Departamento de Engenharia Mecânica | Universidade Federal de Santa Catarina | Campus Universitário, Trindade | Caixa Postal 476 | Florianópolis - SC - Brasil | CEP 88040-970 | Tel.: (48) 3721-9227 Ramal 228 |

E-mail: e.f.vergara@ufsc.br

\section{Fernanda Marros}

DDFH\&B | 3 ChirstChurch Square | D8 | Dublin- Irlanda | Tel.: +353 (83) 840-5443 | E-mail: fmarros@hotmail.com

Stephan Paul

Laboratório de Vibrações e Acústica, Departamento de Engenharia Mecânica | Universidade Federal de Santa Catarina |

E-mail: stephan.paul@ufsc.br

\section{Revista Ambiente Construído}

Associação Nacional de Tecnologia do Ambiente Construído

Av. Osvaldo Aranha, $99-3^{\circ}$ andar, Centro

Porto Alegre - RS - Brasil

$$
\text { CEP } 90035-190
$$

Telefone: +55 (51) 3308-4084

Fax: +55 (51) 3308-4054

www.seer.ufrgs.br/ambienteconstruido

E-mail: ambienteconstruido@ufrgs.br 